\title{
Carbon Fluxes in the Rhizosphere
}

\author{
Weixin Cheng and Alexander Gershenson
}

\subsection{INTRODUCTION}

Terrestrial ecosystems are intimately connected to atmospheric $\mathrm{CO}_{2}$ levels through photosynthetic fixation of $\mathrm{CO}_{2}$, sequestration of $\mathrm{C}$ into biomass and soils, and the subsequent release of $\mathrm{CO}_{2}$ through respiration and decomposition of organic matter. Considering all the pools and fluxes of $\mathrm{C}$ within ecosystems, C-cycling belowground is increasingly being recognized as one of the most significant components of the carbon cycle (e.g., Zak and Pregitzer 1998). Globally, the input of $C$ to the soil has been estimated to be as great as $60 \times 10^{15} \mathrm{~g} \mathrm{yr}^{-1}$, approximately one order of magnitude larger than the global annual rate of fossil fuel burning and other anthropogenic emissions, which is at $6 \times 10^{15} \mathrm{~g} \mathrm{yr}^{-1}$ currently (Post et al. 1990). Thus, small changes in the equilibrium between sinputs and decomposition could have a significant impact on atmospheric $\mathrm{CO}_{2}$ concentrations, which may either exacerbate or reduce the consequence of burning of fossil fuels (Schimel 1995). Belowground $\mathrm{CO}_{2}$ efflux can be partitioned into two distinct processes: (1) rhizosphere respiration or root-derived $\mathrm{CO}_{2}$, including root respiration and microbial respiration utilizing materials released from live roots and (2) microbial decomposition of soil organic matter ( $\mathrm{SOM}$ ), or soil-derived $\mathrm{CO}_{2}$. While the two processes act separately, they may also be linked through rhizosphere interactions, which may exert a stimulative (priming effect) or a suppressive influence on SOM decomposition (Cheng 1999). As a measure of main energy use for the acquisition of belowground resources (e.g., nutrients and water), rhizosphere respiration may range from 30 to 80 percent of total belowground $\mathrm{CO}_{2}$ efflux (Hanson et al. 2000) in various ecosystems. Root-associated C fluxes represent a major portion of the input to and the output from the belowground $C$ pool (Schimel 1995). 
The rhizosphere harbors very high numbers and activities of organisms. Concentrations of microbes in the rhizosphere can reach $10^{10}-10^{12}$ per gram of rhizosphere soil as compared to often $<10^{8}$ in the bulk soil (Foster 1988). Invertebrate density in the rhizosphere is at least two orders of magnitude greater than in the bulk soil. This highly active system associated with plant roots is mainly supported by the carbon input from live roots, which may include sloughed-off materials (cells and mucilage), dead root hairs, and root exudates. This input, along with root turnover, may account for up to 50 percent of the net primary production in various ecosystems (Whipps 1990). The flow of energy and the function of this carbon flux within ecosystems constitute a major area of interest in ecology. To understand the interactions between the three biotic components of the soil, that is roots, microflora and fauna, a necessary first step is to determine how much organic material is contributed to the soil by roots.

In order to facilitate discussion on the various kinds of carbon input into the rhizosphere from roots, we need to first briefly describe the main categories of rhizosphere carbon input and their relationships (Figure 2.1). Among the plant-derived carbon allocated belowground via roots, there are three main components:

1. Roots mass, either alive or dead, which can be normally assessed by physical sampling.

2. Other materials of plant origin remaining in the rhizosphere or the surrounding soil, often called rhizodeposits, which are readily utilized

Total Belowground Allocation

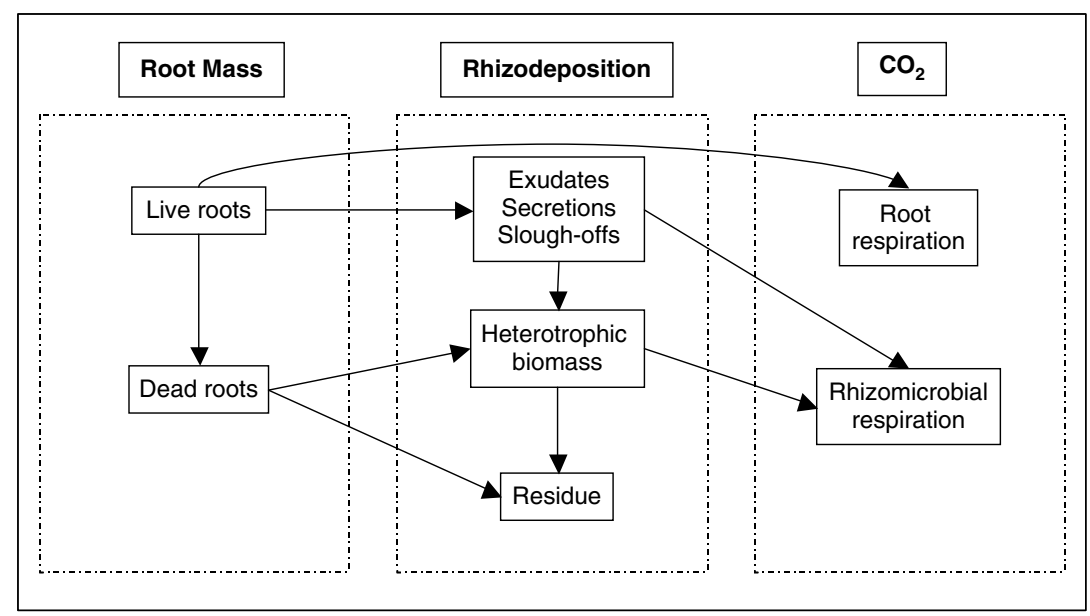

FIGURE 2.1 Main categories of rhizodeposits and their interrelationships. 
and transformed by rhizosphere biota and simultaneously mixed with soil organic materials.

3. Carbon dioxide either from respiration of roots and root symbionts, such as mycorrhizae and nodules, or from rhizosphere microbial respiration utilizing root-derived substrates.

Therefore, studying carbon fluxes in the rhizosphere requires investigation of all three categories mentioned above, in addition to aboveground components. Input by root growth and turnover is extensively covered in Chapter 6. This chapter will primarily focus on the second and the third categories rhizodeposition and $\mathrm{CO}_{2}$ efflux. Because these materials are intimately mixed with soil-derived carbon sources and simultaneously transformed by soil microorganisms, investigating these carbon fluxes requires a suite of methods that either eliminate the soil components, such as using a sterile liquid culture technique, or are capable of tracing root-derived sources separately from soil-derived sources, such as isotope labeling. One of the greatest challenges in rhizosphere research, dictated in large part by the nature of the medium itself, is observation of processes in situ. The methodologies currently available to us often do not allow for such direct observation; however, existing and recently developed methods offer us the opportunity to examine rhizosphere processes with ever-increasing sophistication and approximation of actual soil conditions.

\subsection{QUANTITY AND QUALITY OF RHIZODEPOSITS}

Rhizodeposition was first defined by Whipps and Lynch (1985) as all material lost from plant roots, including water-soluble exudates, secretions of insoluble materials, lysates, dead fine roots, and gases, such as $\mathrm{CO}_{2}$ and ethylene. Because several reviews on this topic have been published (e.g., Whipps 1990; Kuzyakov and Domanski 2000; Nguyen 2003), only a brief summary is included in this chapter.

The sources of organic C-input from roots can be divided into two main groups: (1) water-soluble exudates, for example sugars, amino acids, organic acids, and so on; and (2) water-insoluble materials, for example sloughed cells and mucilage. Materials in the first group are rapidly metabolized by rhizosphere microorganisms. There are three sources of $\mathrm{CO}_{2}$ released by a system of living roots and soil: (1) root respiration; (2) microbial respiration utilizing root-derived materials (rhizo-microbial respiration); and (3) microbial respiration using original soil carbon. This intimate association of root 
respiration and exudation with rhizo-microbial respiration has made studies of root respiration, root exudation, and rhizo-microbial respiration in natural soils very difficult.

The quality or chemical composition of rhizodeposits is an important determinant of the functions and ecological consequences of rhizodeposition. Our understanding of the chemical composition of root exudates and other rhizodeposits is virtually all based on data from experiments using sterile liquid culture methods. Much of the literature on this topic has been reviewed previously (e.g., Whipps 1990). Virtually all kinds of plant molecules and materials can be found in rhizodeposits, although lower molecular weight compounds seem to dominate. Even though labeling methods have been increasingly used to study rhizospheric carbon fluxes, our understanding of the chemical composition of rhizodeposits has not advanced much in the past few decades due to the limitation of available methods. Although the use of Gas Chromatography-Mass Spectrometry (GC-MS) analysis for identification of compounds exuded by roots (Bertin et al. 2003) offers potentially exciting developments in this area, such methodologies still depend heavily on significant simplifications of the rhizosphere system. Studying the chemical composition of rhizodeposits under real soil conditions remains a challenge because of the intimate coupling of microbial utilization and transformation of rhizodeposits.

To provide some examples for the strong effect of the particular methodologies used, if we consider that in the case of using nutrient solution cultures under gnotobiotic conditions, the amount of rhizodeposition has been quantified to be less than $0.6 \mathrm{mg} \mathrm{g}^{-1}$ of root dry weight (Lambers 1987) for seedlings a few weeks old. Due to these highly artificial conditions, this value must represent considerable underestimation. By increasing complexity within the experimental system, for instance by using solid media and adding microorganisms, the amount of rhizodeposition significantly increases (e.g., Barber and Gunn 1974). Using ${ }^{14} \mathrm{C}$-labeling techniques, rhizodeposition has been quantified under more realistic conditions. Values of rhizodeposition, measured by this labeling technique, may range between 30 and 90 percent of the carbon transferred to belowground components of various plant-soil systems (Whipps 1990). Differences in soil type, plant species, plant growth stage, and other experimental conditions employed in various studies may have caused the wide range. For young plants of wheat, barley, or pasture grasses, approximately 20-50 percent of net assimilated carbon is transferred into belowground components, including root biomass ( $\sim 50 \%)$, rhizospherederived $\mathrm{CO}_{2}(\sim 30 \%)$, and soil residues $(\sim 20 \%)$ (Kuzyakov and Domanski 2000). Given that these percentages are averaged across results from labeling experiments using mostly young plants and various experimental conditions, the distribution pattern for carbon allocated belowground seems relatively 
consistent. However, the relative distribution among belowground components is most likely time-dependent, because of carbon transfer from root biomass to $\mathrm{CO}_{2}$ and soil residues via root turnover as the plant ages. The results mentioned above are mostly drawn from experiments using young plants under laboratory conditions. Further studies with longer time span and under settings that bring us closer to in situ conditions are needed to address this issue.

Realistic assessment of the quantity of rhizodeposits in ecosystems remains a challenging task. In the review by Nguyen (2003), data from experiments using both continuous labeling and pulse labeling techniques are compiled and analyzed. The metaanalysis suggests that the total quantity of rhizodeposits is significantly influenced by plant species, plant age, the presence or absence of rhizosphere microorganisms, soil texture, and nitrogen availability. Based on a recent study of 12 Mediterranean species of herbaceous plants (Warembourg et al. 2003), the percentage of assimilated $C$ allocated to belowground differs significantly between major groups of species (i.e., grasses, legumes, and nonlegume forbs), but not significantly different between plant species within each group. Less carbon is allocated belowground as plants age, based on data mostly from annual plant species. The presence of rhizosphere microorganisms substantially increases the quantity of rhizodeposits, as compared to sterile cultures, indicating that sterile cultures should not be used to realistically quantify total rhizodeposits or total carbon allocation to belowground components, although such techniques may allow a qualitative assessment of the types of compounds exuded. Relatively higher (up to 15\%) soil clay contents seem to increase total rhizodeposits; however, nitrogen fertilization is likely to significantly reduce total rhizodeposits. As clearly pointed out in the review by Farrar and Jones (2000), plant carbon allocation imposes the first level of control on the total quantity of rhizodeposits. Therefore, any biotic or environmental conditions that may affect plant carbon allocation will exert controls on rhizodeposition. For example, pulse growth of aboveground components of Quercus rubra seems to vary inversely with rhizosphere respiration, supposedly due to the change of plant $C$ allocation between aboveground and belowground components (Cardon et al. 2002).

A cautionary note is necessary for a reliable use of the above-mentioned results for the assessment of the quantity of rhizodeposits. The majority of the data is taken from experiments of relatively short duration with young plants. Therefore, the interpretation of the data should be limited to such circumstances. The quantitative assessment of rhizodeposits is also methoddependent (Whipps 1990; Kuzyakov and Domanski 2000). Method limitations are considered later in a separate section of this chapter. 


\subsection{RHIZOSPHERE CARBON FLUXES UNDER ELEVATED $\mathrm{CO}_{2}$}

Plants grown under elevated $\mathrm{CO}_{2}$ conditions often exhibit increased growth and a disproportional increase in C allocation to roots (Norby et al. 1986; Matamala and Schlesinger 2000; Norby et al. 2002), total rhizosphere respiration (Cheng et al. 2000), and rhizodeposition (Kuikman et al. 1991; Billes et al. 1993). By using carbon isotope tracers in $\mathrm{CO}_{2}$ enrichment experiments at the small-pot scale, several studies have demonstrated that, compared to ambient $\mathrm{CO}_{2}$ levels, elevated $\mathrm{CO}_{2}$ increased the amount of carbon allocated to the rhizosphere by enhanced root deposition or total rhizosphere respiration (Hungate et al. 1997; Cheng and Johnson 1998). In general, total carbon input to the rhizosphere is significantly increased when plants are grown under elevated $\mathrm{CO}_{2}$ (Table 2.1) (also see Chapter 6).

The degree of $\mathrm{CO}_{2}$ enhancement of rhizosphere respiration could be much higher than enhancement of root biomass (Table 2.2). In a continuous ${ }^{14} \mathrm{C}$ labeling study using wheat, Lekkerkerk et al. (1990) reported that the wheat plants grown under the elevated $\mathrm{CO}_{2}$ treatment produced 74 percent more rhizosphere-respired $C$ and only 17 percent more root biomass compared to the ambient treatment. Hungate et al. (1997), in a microcosm experiment with mixed grasses, reported that elevated $\mathrm{CO}_{2}$ enhanced total rhizosphere deposition by 56 percent and root biomass by less than 15 percent. Cheng and Johnson (1998) reported that, compared with the ambient $\mathrm{CO}_{2}$ treatment, wheat rhizosphere respiration rate increased 60 percent and root biomass increased only 26 percent under the elevated $\mathrm{CO}_{2}$ treatment. Two potential mechanisms could be posited as potential causes of these results. First, roots grown under elevated $\mathrm{CO}_{2}$ exuded more and had higher turnover rates than roots grown under the ambient treatment, resulting in a more than proportional increase in total rhizosphere respiration under elevated $\mathrm{CO}_{2}$. Second, rhizosphere microbial associations were more enhanced under elevated $\mathrm{CO}_{2}$ than under ambient $\mathrm{CO}_{2}$, resulting in higher rhizosphere microbial activities per unit of root growth.

Some evidence supports the first hypothesis. Using the isotopic trapping method (Cheng et al. 1993, 1994), approximately a 60 percent increase in soluble $\mathrm{C}$ concentration was found in the rhizosphere when wheat plants were grown under elevated $\mathrm{CO}_{2}$ compared to ambient $\mathrm{CO}_{2}$, indicating that roots grown under elevated $\mathrm{CO}_{2}$ exuded more soluble $\mathrm{C}$ (Cheng and Johnson 1998). Pregitzer et al.'s (see Chapter 6) review evidence that root turnover rates are higher for plants grown under elevated $\mathrm{CO}_{2}$ than under ambient. However, the amount of extra $\mathrm{C}$ input to the rhizosphere due to the enhanced root turnover under elevated $\mathrm{CO}_{2}$ was expected to be low in most tracer studies of short duration, since the life span of the roots was probably longer than 


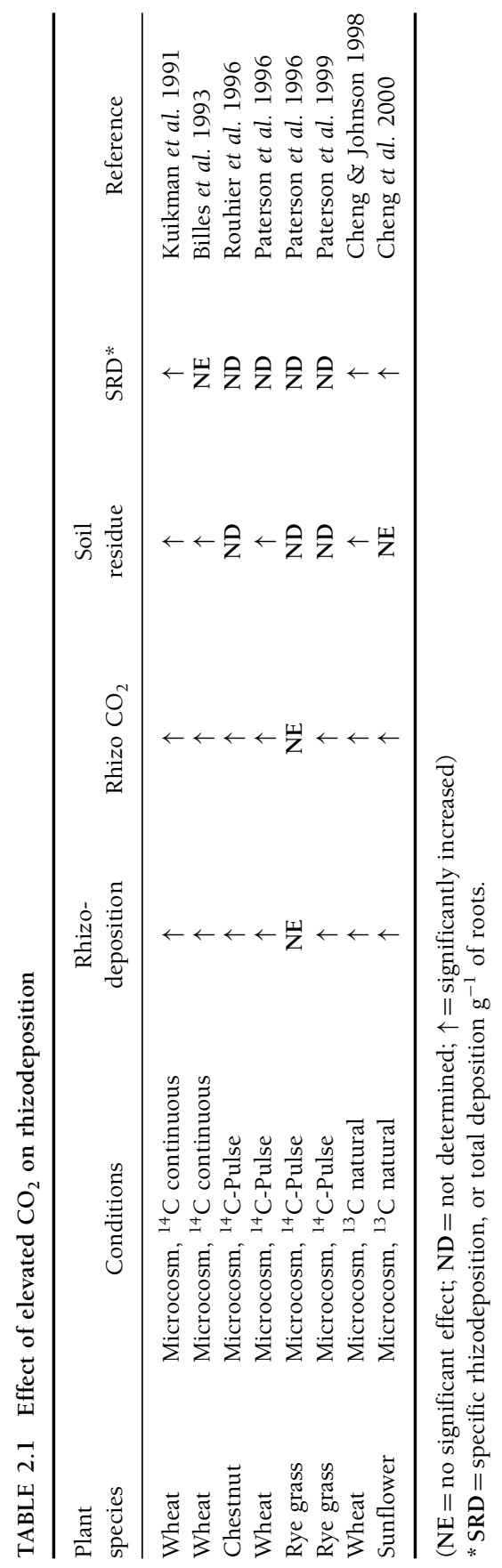




$\begin{aligned} & \text { TABLE } 2.2 \\
& \text { efflux in response to elevated atmospheric } \mathrm{CO}_{2} \text { concentrations, } \\
& \text { calculated as (Elevated-Ambient)/Ambient } \times 100\end{aligned}$
\begin{tabular}{lcl}
\hline Root biomass & Rhizosphere $\mathrm{CO}_{2}$ & Reference \\
\hline 17 & 74 & Lekkerkerk et al. 1990 \\
15 & 56 & Hungate et al. 1997 \\
26 & 60 & Cheng \& Johnson 1998 \\
50 & 96 & Cheng et al. 2000 \\
\hline
\end{tabular}

the duration of the experiment (Eissenstat and Yanai 1997). Enhanced root exudation was probably the major component of this extra $C$ input to the rhizosphere in these short experiments. Enhanced root turnover under elevated $\mathrm{CO}_{2}$ for forest ecosystems might contribute more since root turnover was one of the important processes responsible for $\mathrm{C}$ input in forests (see Chapter 6). In a deconvolution analysis of soil $\mathrm{CO}_{2}$ data from the Duke Free-Air $\mathrm{CO}_{2}$ Enrichment (FACE) experiment, Luo et al. (2001) indicated that fine root turnover is a major process adding $\mathrm{C}$ to the rhizosphere in response to elevated $\mathrm{CO}_{2}$, and that root respiration and exudation are less affected by elevated $\mathrm{CO}_{2}$. The second hypothesis, suggesting that enhancement of rhizosphere respiration under elevated $\mathrm{CO}_{2}$ is linked to enhanced root-microbial associations, is also supported by evidence in the literature. Elevated $\mathrm{CO}_{2}$ increased both the percentage of infection of vesicular-arbuscular mycorrhizae and percentage of infection of ectomycorrhizae (see Chapter 4). Elevated $\mathrm{CO}_{2}$ also increased symbiotic $\mathrm{N}_{2}$-fixation across several types of associations (Arnone and Gordon 1990; Thomas et al. 1991; Tissue et al. 1997). However, direct evidence of higher rhizosphere symbiotic activities per unit of root growth under elevated $\mathrm{CO}_{2}$ is still lacking.

\subsection{FUNCTIONAL CONSIDERATIONS}

The large quantities of rhizodeposits apparently represent a significant portion of the plant carbon balance and an important source of substrates for soil organisms. In addition to the quantitative significance, their functional significance warrants some attention. What does rhizodeposition do to the plants, to the soil biota, and to the nutrient cycling processes in the soil?

As to the plants, is rhizodeposition a simple passive wasting process, a passive loss of soluble materials by diffusion, an overflow of assimilates when other sinks for photosynthate are limited, active secretion and excretion, or all of the above? Based on data from a liquid culture experiment, root exudation of amino acids and sugars seems to occur passively through diffusion process, 
and is affected by membrane integrity (Jones and Darrah 1995). Some evidence also suggests that root exudation and respiration may act as overflow mechanisms for excessive photosynthate accumulation (Herald 1980; Lambers 1987). However, many studies in plant nutrition have demonstrated that roots secrete organic acids and other materials for the purpose of nutrient acquisition, such as phosphorus mobilization and iron activation (Marschner 1995).

For soil microflora and fauna, do rhizodeposits act as an important base for the soil food web, or a component of the molecular control points for the coevolution of plants and rhizosphere organisms, or both? Some recent work seems to suggest that rhizodeposits provide the base for a very important part of the soil food web (Garrett et al. 2001; see Chapters 3 and 5). Some of the compounds in rhizodeposits may also act as messengers in regulating the interactions between roots and soil microflora and between different kinds of rhizosphere organisms (Hirsch et al. 2003; Phillips et al. 2003; see Chapters 1 and 3).

Our understanding of the ecological functions of rhizodeposition relies heavily on our ability to study the chemical composition of rhizodeposits. Because the majority of data related to functional understanding are generated from liquid culturing experiments, the applicability of these results to a real soil environment is also limited. The use of reporter genes (Jaeger et al. 1999; Killham and Yeomans 2001; see Chapter 1) may offer new hopes for improvements. For example, the quantity and the chemical forms of some root exudates can be investigated in real soil environment with the help of reporter genes (Jaeger et al. 1999). Evidence from some studies supports a general belief that rhizodeposition exerts strong positive or negative controls on soil organic matter decomposition (Cheng and Kuzyakov 2005). However, very little is known about the role of the rhizosphere effect on decomposition in shaping plant adaptation to various soil environments in the long term. If the rhizosphere effect is closely connected to plant photosynthesis and rhizodeposition (Högberg et al. 2001; Kuzyakov and Cheng 2001), it is conceivable that the rhizosphere effect should be beneficial to plants, and thereby enhance their fitness. Among possible benefits, enhanced nutrient acquisition is often suggested (e.g., Hamilton and Frank 2001). Other benefits may include suppression of root pathogens by supporting healthy microbial communities (e.g., Whipps 2001), conditioning of soil paths for root growth, and improving soil structures and chemical environment, such as $\mathrm{pH}$ adjustment (Marschner 1995). If all these benefits occur, the rhizosphere effect on soil organic matter decomposition should be a result of evolutionary processes operating between plants and soil organisms in the overall rhizosphere continuum from incidental to highly symbiotic (see Chapters 1, 3 for more information). Different rhizosphere mechanisms should be selected under different plant and soil environments. This argument seems to be supported 
by the fact that different plant-soil couplings produce different rhizosphere effects on soil organic matter decomposition (Fu and Cheng 2002; Cheng et al. 2003). Future research is needed to fully illuminate the evolutionary aspects of rhizodeposition.

\subsection{MICROBIAL ASSIMILATION EFFICIENCY OF RHIZODEPOSITS}

Microbial carbon assimilation efficiency is commonly defined as microbial biomass produced as a proportion of total carbon utilized. It is also called the yield factor. Accumulated evidence suggests that a big proportion of root exudates is utilized and released as $\mathrm{CO}_{2}$ in a very short period of time; only a small portion becomes microbial biomass (Dyer et al. 1991; Harris and Paul 1991). The microbial assimilation efficiency of these exudates (6.5-15\%; Helal and Sauerbeck 1989; Liljeroth et al. 1990; Martin and Merckx 1992), is considerably lower than the theoretical maximum of 60 percent (Payne 1970) and of other sources of carbon in the soil. The microbial assimilation efficiency is 61 percent for glucose added to the soil after about 40 hours of incubation (Elliott et al. 1983), 27 percent after 61 weeks of incubation (Johansson 1992), and 47 percent for rye shoots added to the soil after 7 weeks of incubation (Cheng and Coleman 1990). Why is the microbial assimilation efficiency of root exudates so low? What mechanisms are there behind this lower efficiency?

The occurrence of biological $\mathrm{N}_{2}$-fixation in the rhizosphere may contribute to the low microbial assimilation efficiency of root exudates. Biological dinitrogen fixation requires high amounts of energy, especially those of an associative nature. At least 16 ATP molecules are consumed to convert one $\mathrm{N}_{2}$ to two $\mathrm{NH}_{3}$ molecules, in addition to other processes required for associative $\mathrm{N}_{2}$-fixation. If a large proportion of root exudates is used by diazotrophs in the rhizosphere, the assimilation efficiency of root exudates will be much lower than if it is being used by non-nitrogen-fixing microbes. Several studies (Liljeroth et al. 1990; Van Veen et al. 1991) have shown that the assimilation efficiency of root-derived materials is higher when more nitrogen fertilizer has been used. It is likely that nitrogen fertilization suppresses diazotrophic activity in the rhizosphere, which contributes to higher assimilation efficiency. It is widely known that rhizosphere is one of the important sites for potential associative free-living nitrogen fixation, due to the favorable conditions in the rhizosphere (supply of carbon source, mainly root exudates, and the relatively low oxygen potential caused by root and microbial respiration in the rhizosphere). The list of free-living nitrogen-fixing bacteria continues to grow as more genera and species are described. It seems that most plant species in natural environment 
are colonized to some degree by free-living diazotrophs (e.g., Kapulnik 1991). The contribution of biologically fixed $\mathrm{N}_{2}$ by free-living diazotrophs can be substantial in some ecosystems, such as savanna grasslands (Abbadie et al. 1992). However, this subject remains controversial in broader perspectives. Some reported values of fixed $\mathrm{N}_{2}$ by free-living diazotrophs exceed that which can possibly be supported by the estimated amount of carbon available to the diazotrophs. Much of the controversy stems from the energetic requirement of nitrogen fixation process and the estimated amount of carbon available to the rhizosphere diazotrophs (Jones et al. 2003). Central to this controversy is the flow of carbon to root-associated diazotrophs in soil-grown plants, since most of the estimates of root exudation are based on gnotobiotic experiments. A better understanding of the contribution of free-living nitrogen-fixing bacteria to the $\mathrm{N}$ economy of the rhizosphere requires more suitable methods that allow ecological studies under natural environmental conditions (Kapulnik 1991; Jones et al. 2003).

Accelerated turnover rates of rhizosphere microbial biomass due to faunal grazing may be another explanation for the low microbial assimilation efficiency of root exudates as measured. Faunal grazing on rhizosphere bacteria and fungi has been suggested as a key factor of the "priming effect" of root exudates (Ingham et al. 1985; see Chapters 3and 5). The high population density of bacteria in the rhizosphere (Foster 1988) may attract many grazers. The densities of both protozoa and bacterial-feeding nematodes have been shown to be higher in the rhizosphere than in the bulk soil (Ingham et al. 1985). Faunal grazing will increase the turnover rate of carbon and nitrogen in the rhizosphere, and subsequently result in a lower amount of exudate carbon or nitrogen in microbial biomass form, and higher amount being released as $\mathrm{CO}_{2}$ (see Chapter 3). A rapid turnover rate (50\% loss in 1 week) of microbial biomass- $C$ formed from utilizing root exudates has been reported in a study with pine seedlings grown in soil using a pulse-labeling technique (Norton et al. 1990).

Another possible cause of the lower microbial assimilation efficiency of root exudates in the rhizosphere is the limitation of mineral nutrients such as nitrogen due to the competition with root uptake. Because of the abundant supply of available carbon in the form of exudates, microbial growth in the rhizosphere may be highly limited by mineral nutrients. For example, microbial respiration rate in the young wheat rhizosphere is not stimulated by addition of glucose (Cheng et al. 1994), but the assimilation efficiency of root-derived materials is higher when more nitrogen fertilizer has been used (Liljeroth et al 1990; Van Veen et al. 1991).

The microbial assimilation efficiency of root exudates has deeper implications for carbon cycling in terrestrial ecosystems. It determines the flux of carbon entering the soil organic matter pool through living roots. As 
predicted global climatic change and the doubling of atmospheric $\mathrm{CO}_{2}$ concentration in the near future may increase plant primary production and subsequently increase root exudate production (Kuikman et al. 1991), the microbial assimilation efficiency of root exudates will be a determinant as to what proportion of this increased primary production will be transferred to the soil organic carbon pool. If we assume that approximately 5 percent of the current global terrestrial primary production $\left(\sim 120 \times 10^{15} \mathrm{yr}^{-1}\right)$ is in the form of root exudates, which equals to $6 \times 10^{15} \mathrm{~g} \mathrm{Cyr}^{-1}$ (similar to the annual rate of current global fossil fuel consumption), and that a doubling of atmospheric $\mathrm{CO}_{2}$ concentration will increase root exudate production by 70 percent (see Table 2.2), the amount of the $\mathrm{CO}_{2}$-enhanced root exudate production would be $4.2 \times 10^{15} \mathrm{~g} \mathrm{C} \mathrm{yr}^{-1}$. If microbial utilization of exudates is complete (or $100 \%$ used), a range of microbial assimilation efficiencies of 5-20 percent will mean that the amount of the $\mathrm{CO}_{2}$-enhanced carbon input into the soil via this route will vary between $0.21 \times 10^{15} \mathrm{~g} \mathrm{Cyr}^{-1}$ and $0.84 \times 10^{15} \mathrm{~g} \mathrm{C} \mathrm{yr}^{-1}$, or from 3.5 to 14 percent of the annual rate of current global fossil fuel consumption.

\subsection{TEMPORAL DYNAMICS OF EXUDATION AND RESPIRATION}

The timing of root exudation determines how closely rhizosphere processes are linked with plant photosynthesis and aboveground physiology, and therefore the response time of rhizosphere activities to any change of environment aboveground. Pertaining to the temporal connections of root respiration, exudation, and rhizosphere microbial respiration of exudates, some pulse-labeling studies have reported contradictory results. Some studies seem to indicate that there exists a noticeable time lag between the time when root-respired ${ }^{14} \mathrm{C}$-labeled $\mathrm{CO}_{2}$ is released to the rhizosphere and the time of appearance of ${ }^{14} \mathrm{C}$-labeled $\mathrm{CO}_{2}$ from rhizo-microbial respiration of new root exudates (Warembourg and Billes 1979; Kuzyakov and Domanski 2002). This time lag may occur either between root respiration of the ${ }^{14} \mathrm{C}$-labeled photosynthates and the appearance of the new rhizodeposits or between the time of rhizodeposit appearance in the rhizosphere and the time of microbial uptake and utilization, or both. Some other studies did not detect any meaningful time lag between these processes (Cheng et al. 1993, 1994). Understanding of the temporal aspect of these processes is required when dynamic models are used to simulate rhizosphere carbon fluxes (Kuzyakov et al. 1999; Luo et al. 2001). This assumed time lag has also been used to separate root respiration from rhizosphere microbial respiration (Kuzyakov et al. 1999, 2001).

Using ${ }^{14} \mathrm{C}$ pulse-labeling techniques in a liquid culture of young wheat plants, Warembourg and Billes (1979) found that there was more than one 
distinctive peak of ${ }^{14} \mathrm{CO}_{2}$ release from the rhizosphere when microorganisms were present. The first peak of ${ }^{14} \mathrm{CO}_{2}$ release was assumed to be produced from root respiration, whereas microbial utilization of rhizodeposits was hypothesized responsible for the second peak, indicating that there was a time lag between the time when root-respired ${ }^{14} \mathrm{C}$-labeled $\mathrm{CO}_{2}$ is released to the rhizosphere and the time of appearance of ${ }^{14} \mathrm{C}$-labeled $\mathrm{CO}_{2}$ from rhizo-microbial respiration of new rhizodeposits. The time interval between the two peaks was roughly 24 hours. This time lag hypothesis was also supported by the fact that the occurrence of the second ${ }^{14} \mathrm{C}$-labeled $\mathrm{CO}_{2}$ peak is also coupled with an accumulation of ${ }^{14} \mathrm{C}$-labeled rhizodeposits in the culturing solution of the non-sterile system. However, a small but visible second peak also appeared in the sterile treatment at a similar time interval, which could not be explained by the time lag hypothesis. Multiple peaks of ${ }^{14} \mathrm{CO}_{2}$ release from the rhizosphere were also reported by Nguyen et al. (1999) and Kuzyakov (2002). In a study of continuous release of rhizospheric $\mathrm{CO}_{2}$ from 5-week-old maize plants, Nguyen et al. (1999) showed that there were two clearly distinguishable peaks of ${ }^{14} \mathrm{CO}_{2}$ release after the start of the ${ }^{14} \mathrm{C}$-labeling, and that the time interval between the two peaks was 13.6 hours. This 13.6-hour interval between the two peaks did not correspond to a 24-hour diurnal cycle. Using a continuous liquid elution method, Kuzyakov and Siniakina (2001) chased rhizosphere release of both ${ }^{14} \mathrm{CO}_{2}$ and exudates for 4 days after a pulse labeling of Lolium perenne with ${ }^{14} \mathrm{CO}_{2}$. Their study showed that there were clearly two peaks of exudate release and a much smaller second peak of ${ }^{14} \mathrm{CO}_{2}$ release after the pulse labeling. The time interval between the first peak and the second peak roughly corresponded to the diurnal cycle. The authors believed that the dynamics of exudate release was mainly driven by photosynthate loading during the light period and the consumption of photo-assimilates during the dark period. The study also showed that the ${ }^{14} \mathrm{C}$-labeled new photosynthate was simultaneously utilized in both root respiration and exudation processes, and that there was no detectable time lag between them. Their results could not render a clear answer to the question of whether or not there was a time lag between the time of rhizodeposit appearance in the rhizosphere and the time of microbial uptake and utilization, because root respiration could not be separately measured from rhizosphere microbial respiration in their experiment. The answer to this question could be found in one of our own studies (Cheng et al. 1993). In the study, root respiration and rhizosphere microbial respiration were separately measured for a short period of time after a pulse labeling by using an isotope trapping technique with the addition of ${ }^{12} \mathrm{C}$-glucose solution. The addition of glucose solution reduced the release of ${ }^{14} \mathrm{CO}_{2}$ from the wheat rhizosphere by as much as 50 percent, primarily due to the reduction of rhizosphere microbial respiration because of substrate competition. This result clearly indicated that exudates were instantly utilized 
and converted into ${ }^{14} \mathrm{CO}_{2}$ by the rhizosphere microorganisms. No detectable time lag existed between the time of exudate appearance in the rhizosphere and the time of microbial uptake and utilization. This conclusion may also be inferred indirectly from the fact that adding sugar solution to soils commonly produces an instant pulse of $\mathrm{CO}_{2}$ from microbial metabolism (Anderson and Domsch 1978). However, this may only apply to the case of readily available water-soluble exudates. It is probable that there exists a detectable time lag in hours or days either between root respiration of the ${ }^{14} \mathrm{C}$-labeled photosynthates and the appearance of the new insoluble components of the rhizodeposits or between the time of appearance of the new insoluble components of the rhizodeposits and the time of microbial uptake and utilization of such components, or both. For example, microbial utilization of insoluble rhizodeposits may occur 2-5 days after the start of the pulse labeling (Warembourg and Billes 1979; Kuzyakov et al. 2001). Further studies are needed to advance our understanding on this issue.

In reconciliation of the above-mentioned results, we constructed a timeseries model of carbon releases in the rhizosphere after a pulse labeling with ${ }^{14} \mathrm{CO}_{2}$ (Figure 2.2). The model depicts the following two points of understanding: (1) Current photo-assimilate production and translocation imposes the first level of control on the release of carbon sources from roots to the rhizosphere, because both exudate production and the efflux of rhizosphere $\mathrm{CO}_{2}$ correspond to the diurnal cycle of photosynthesis; and (2) The occurrence

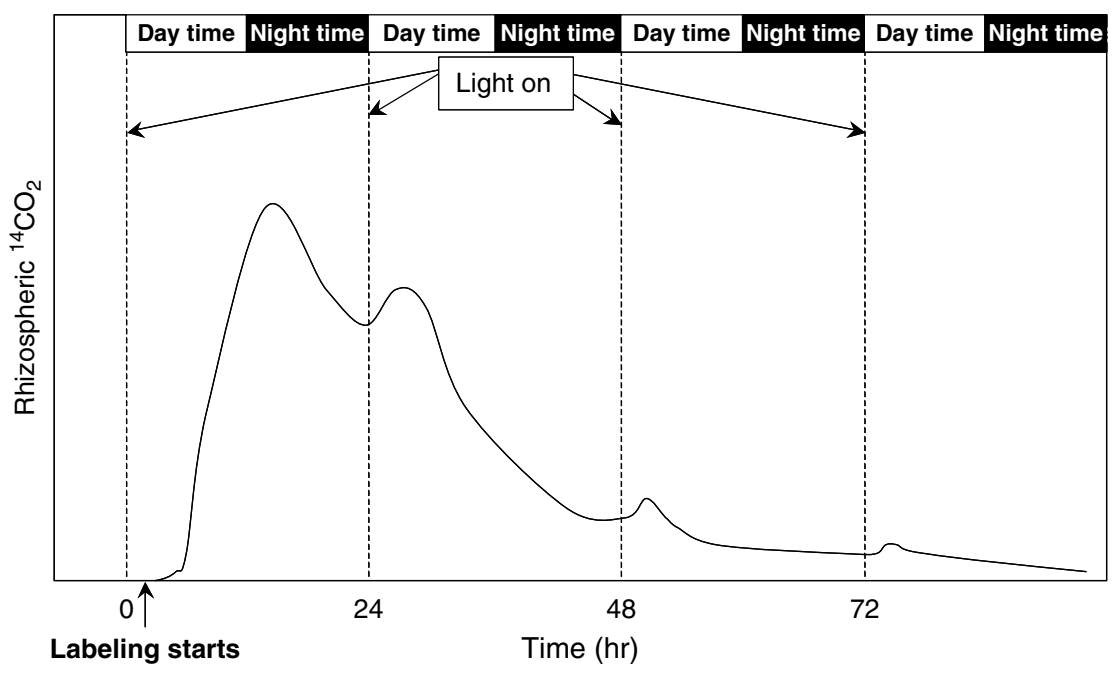

FIGURE 2.2 An idealized model of temporal dynamics of ${ }^{14} \mathrm{CO}_{2}$ released from the rhizosphere after a pulse labeling. 
of more than one peaks of ${ }^{14} \mathrm{CO}_{2}$ release after a pulse labeling does not necessarily indicate that there exists a time lag either between root respiration of the ${ }^{14} \mathrm{C}$-labeled photosynthates and the appearance of the new exudates or between the time of exudate appearance in the rhizosphere and the time of microbial uptake and utilization. As mentioned above, the time interval between the first peak and the second peak varies among different experiments, for example approximately 24 hours in Warembourg and Billes (1979), but 13.6 hours in Nguyen et al. (1999). The timing of the first peak is largely determined by the starting time and the duration of the labeling. However, the onset of the second peak and the third peak generally occur at the start of the light period (Todorovic et al. 2001). Therefore, different starting time and duration of the labeling in reference to the regular diurnal cycle give different time intervals between the initial two peaks among these experiments.

The discussion of the "time lag" issue is primarily based on data from pulse labeling studies of young herbaceous plants. The time dynamics of rhizosphere carbon release from woody plants awaits further investigation.

\subsection{METHODS FOR STUDYING RHIZOSPHERE CARBON FLUXES}

Many researchers may agree with the statement that method development has been, and remains, a key prerequisite for advancing rhizosphere science. Our understanding of carbon fluxes in the rhizosphere has significantly increased as new methods and approaches have been developed and used in rhizosphere research in the last several decades. Early studies utilized nutrient solutionbased methods in order to estimate rates of rhizodeposition and assess the composition of root exudates (Whipps 1990). Various isotopes of carbon have been used to trace carbon pathways within the plant and through the plant-soil continuum (Nguyen 2003) using various labeling methodology. Recently, a series of molecular techniques have become available to evaluate the composition and identify sources of exudates (Killham and Yeomans 2001; Marschner 2003). However, the available methods have so far fallen short of providing accurate estimates of in situ rhizodeposition. Several factors contribute to this lack of data. A review of the literature provides a series of factors that are thought to influence rhizodeposition. These include root impedance (soil type, structure), nutrient status, $\mathrm{pH}$, presence of microbial and faunal populations, temperature, light intensity, $\mathrm{CO}_{2}$ concentration, stage of plant development, and presence of mycorrhizal associations (Whipps 1990; Killham and Yeomans 2001).

This complexity of potential interactions introduces questions of applicability of results of studies available to date for modeling of carbon movement 
in the rhizosphere in situ (Toal et al. 2000), especially considering that the vast majority of studies are performed in controlled conditions in the laboratory or in a greenhouse. Modeling is further complicated by the large variety of measurement units used for reporting results, which make comparisons between methods, as well as comparisons of different studies utilizing the same method, difficult.Likewise, the choice of organisms for the majority of the experiments introduces additional sources of bias into the resulting data, since most of the experiments use young annual plants, largely cereals. Cereals have been bred to allocate a larger portion of biomass aboveground, which skews carbon budgeting attempts. However, the methods available now have produced results that shed light onto rhizosphere carbon dynamics. The main advantages and disadvantages of five major kinds of methods were summarized in Table 2.3.

TABLE 2.3 Main Advantages and Disadvantages of Methods used in Studying C fluxes in the rhizosphere

\begin{tabular}{|c|c|c|}
\hline Method & Benefits & Drawbacks \\
\hline Nutrient Solution & $\begin{array}{l}\text { Allows identification of } \\
\text { exudate materials and sites } \\
\text { of exudation. }\end{array}$ & $\begin{array}{l}\text { Far removed from real } \\
\text { conditions, does not allow } \\
\text { quantification of carbon lost } \\
\text { through respiration. }\end{array}$ \\
\hline Pulse-Chase & $\begin{array}{l}\text { Provides information on } \\
\text { carbon pathways in relation } \\
\text { to plant ecophysiology. The } \\
\text { label is preferentially found } \\
\text { in labile (non-structural) } \\
\text { carbon pools. }\end{array}$ & $\begin{array}{l}\text { Unable to provide balances for } \\
\text { ecosystem carbon. Cannot } \\
\text { distinguish between root } \\
\text { respired } C \text { and } C \text { that } \\
\text { results from microbial } \\
\text { mineralization of root } \\
\text { derived carbon. }\end{array}$ \\
\hline $\begin{array}{c}\text { Continuous } \\
\text { Labeling }\end{array}$ & $\begin{array}{l}\text { Allows creation of carbon } \\
\text { budgets. Label distributed } \\
\text { homogeneously throughout } \\
\text { the plant. Allows estimation } \\
\text { of carbon flux through soil } \\
\text { microbial biomass. }\end{array}$ & $\begin{array}{l}\text { Expensive, cumbersome, does } \\
\text { not distinguish between } \\
\text { root respiration and } \\
\text { rhizosphere decomposition } \\
\text { of root-derived materials. }\end{array}$ \\
\hline Natural Abundance & $\begin{array}{l}\text { Relatively simple techniques, } \\
\text { do not require use of } \\
\text { radioactive materials, allow } \\
\text { distinction between soil and } \\
\text { plant carbon decomposition. }\end{array}$ & $\begin{array}{l}\text { Due to high level of noise in } \\
\text { the system only useful for } \\
\text { distinguishing large } \\
\text { differences. }\end{array}$ \\
\hline Reporter Genes & $\begin{array}{l}\text { Allows identification of } \\
\text { spatial sources and } \\
\text { compounds released into the } \\
\text { rhizosphere. }\end{array}$ & $\begin{array}{l}\text { Requires specialized equipment } \\
\text { and training, does not } \\
\text { provide data on carbon lost } \\
\text { through respiration. }\end{array}$ \\
\hline
\end{tabular}

After Killham and Yeomans (2001), Whipps (1990) 
Nutrient culture studies have provided a significant amount of information on the types of compounds exuded by plant roots into the rhizosphere, and allow differentiation of carbon lost as low molecular weight compounds from carbon lost as sloughed off root cells and root hairs (Nguyen 2003). However, inherent in the nutrient culture methodologies is the separation of the root-microbial complex of the rhizosphere, which has a high potential of disrupting the feedback mechanisms that may drive exudation. Likewise, resorption of exudates makes final estimates questionable. When physical barriers, such as sterile sand or glass beads, are introduced, the amount of exudates ranges tremendously; for instance, in Hordeum vulgare the range for exudates was 76-157 $\mu$ g plant $^{-1}$ day $^{-1}$ (Barber and Gunn 1974); and in maize the addition of glass ballotini to mimic soil texture increased exudation from 94 to $280 \mathrm{mg} \mathrm{g}^{-1}$ dry weight of root over 5 days (Whipps 1990). Studies that rely on this technique often use seedlings, primarily of herbaceous plants, which may create additional bias. Lack of soil fauna and symbiotic organisms, which have the potential to influence rhizodeposition (see Chapters 3 and 4), also prohibitively limit the application of results from nutrient culture studies. Although nutrient culture studies have severe limitations for the application of the results to our understanding of in situ processes, recent advances in GC-MS analysis, based on the liquid culture technique, may allow a further understanding of the types of compounds exuded by plants, although quantitative information resulting from these methodologies remains suspect.

Pulse-chase studies involve exposing a plant to various isotopes of carbon for a short period of time, with subsequent evaluation of the sinks of this assimilated carbon both within the plant and in the rhizosphere. Pulsechase studies largely provide information on $\mathrm{C}$ fluxes in relation to plant ecophysiology. Different lengths of labeling and chasing periods have been used in various experiments, which make comparison between different studies difficult. An analysis of 43 studies shows that exposure to the isotope ranges from 20 minutes to 720 hours with a mean of 6 and a median of 108 hours, with similar scales of variation in the duration and timing of the chase. However, a recent study indicates that the relative distribution of the tracer is not significantly influenced by the duration of the labeling, as long as the subsequent chasing period is long enough (Warembourg and Estelrich 2000). Due to the short exposure time in most experiments, the pulse-chase method cannot provide data for the construction of carbon budgets of the rhizosphere, nor does it allow partition between root and microbial respiration. Additional complications arise because carbon distribution determined at one plant development stage cannot be applied to others, which presents a problem since most experiments are done on very young plants (Kuzyakov and Domanski 2000). 
Continuous labeling studies provide data that allow construction of complete carbon accounting models. However, most continuous labeling techniques are cumbersome, expensive, and not applicable in field situations. Continuous labeling studies are generally short term (mean 37, median 28 days). Methodological difficulties are numerous, for instance separation of very fine roots from soil is difficult, therefore some may be left in the sample, affecting the resulting data on carbon movement into soil.

A recent variation on the continuous labeling studies is the natural abundance method (e.g., Cheng 1996; Hanson et al. 2000), which uses naturally occurring isotopic composition differences to separate root- from soil-derived materials, and allows development of belowground carbon budgets without the expensive and difficult experimental setups, and does not require separation from the ambient atmosphere. However, several researchers have pointed out that this is a noisy system (Killham and Yeomans 2001), and therefore only large differences between treatments can be distinguished. Due to the fact that it uses unnatural plant-soil combinations, the applicability of the results obtained by this method to ecosystem carbon accounting may come under question.

Recent advances in molecular techniques allow tracing of low molecular weight compounds exuded by the roots in the rhizosphere, both providing spatial analysis of exudation sites and offering an assessment of the classes of compounds exuded by the roots (Killham and Yeomans 2001). However, these techniques require a set of very specific molecular tools and skills, as well as expensive equipment for genetic modification of microbial populations. Moreover, they do not provide data on carbon lost from the rhizosphere due to respiration.

In examining existing methods, and the reliability of the results obtained through their utilization, as well as during development of new methodologies, we need to recognize the level of abstraction from in situ conditions that the methods entail. Evaluating the wealth of studies that show how dramatically external factors can affect rhizosphere processes, method development should aim toward more precise replication of field conditions in the laboratory, and ideally the development of robust methodologies for in situ minimal disturbance investigations of rhizosphere processes.

\subsection{PROSPECTS FOR FUTURE RESEARCH}

In the past decades, some significant progress has been made in our pursuit of understanding rhizosphere $C$ fluxes. For example, the strong top-down control of rhizosphere $C$ fluxes by photosynthesis has been highlighted at several levels of resolution from tree plantations (e.g., Högberg et al. 2001), to small 
plots in a grassland (e.g., Craine et al. 1999), to well-controlled laboratory experiments (e.g., Kuzyakov and Cheng 2001). Initial understanding of the influence of elevated atmospheric $\mathrm{CO}_{2}$ concentrations on rhizosphere $\mathrm{C}$ fluxes has been attended both in laboratory experiments and in field experiments (e.g., Cheng 1999; Luo et al. 2001). The natural abundance of ${ }^{13} \mathrm{C}$ has increasingly been used in studies of rhizosphere $C$ fluxes, which may offer some new and complementary advantages, as compared to commonly used ${ }^{14} \mathrm{C}$-labeling methods (e.g., Cheng et al. 2003). Methods and tools from molecular biology have been employed in studies of rhizosphere $C$ fluxes (see Killham and Yeomans 2001). In perspective of future research on C fluxes in the rhizosphere, we consider the following as some of the key areas in rhizosphere research in the near future.

\section{Much Less Is Known About Carbon Fluxes In Tree RHIZOSPHERES}

In the past few decades, research on carbon fluxes in the rhizosphere has been mostly restricted to cereal crops (Nguyen 2003). Little work has been done on carbon fluxes in tree rhizospheres. Forests have been identified as important processors of carbon (Houghton 1993). However, our lack of understanding of below-ground carbon fluxes in forest systems, and specifically the role of roots, is the greatest limitation in our ability to assess the contribution of forests as global carbon processors (e.g., Schimel 1995). According to current estimates, total rhizosphere respiration may contribute, on average, approximately 50 percent of the total $\mathrm{CO}_{2}$ released from belowground components in forest ecosystems (Hanson et al. 2000), and ranges from 30 to as high as 90 percent (Bowden et al. 1993). Therefore, carbon fluxes in the rhizosphere of forest ecosystems represent important belowground processes responsible for $\mathrm{C}$ release. However, the controlling mechanisms and the functional role of this large carbon expenditure are not well understood. It is commonly known that temperature strongly regulates fine root respiration in an exponential fashion (Ryan et al. 1996). Several studies have demonstrated that rhizosphere respiration is tightly coupled with photosynthesis in annual plants (Kuzyakov and Cheng 2001) with very short time lags (minutes to hours). As shown in a study by Horwath et al. (1994) using ${ }^{14} \mathrm{C}$ pulse labeling, time lags in the linkage between aboveground photosynthesis and rhizosphere respiration can be as short as a few days for very young hybrid poplars. The time lag has been reported to be in the range of 7-60 days in a study using ${ }^{13} \mathrm{C}$ signal from the FACE treatment at a loblolly pine site (Luo et al. 2001). As shown in a large-scale tree girdling experiment with a boreal Scots pine forest, the reduction in total soil $\mathrm{CO}_{2}$ efflux caused by the termination of current photoassimilate supply to the roots system can be as high as 37 percent within 
5 days, and 54 percent within 1-2 months (Högberg et al. 2001). However, the underlying mechanisms responsible for the coupling between photosynthesis and rhizosphere respiration remain largely unknown.

\section{Linking C Dynamics In The Rhizosphere To General Models Of C Allocation}

Although the introduction of various isotope tracer methods has lead to meaningful progress in assessing the quantity of rhizosphere $C$ fluxes, less work has been done in conjunction with the framework of overall $C$ allocation beyond a common practice of expressing $C$ flux as a percentage of gross or net primary production. However, it is crucial to understand $C$ fluxes in the rhizosphere in the context of mechanistic relations with plant $C$ allocation and its controls, if one main purpose of the research is to scale the results to be generally applicable to a larger system or other kinds of systems. Most research so far has provided data either on the quantity of $C$ fluxes in the rhizosphere for a particular system or on the qualitative influence of some environmental factors, such as lighting, elevated $\mathrm{CO}_{2}$, grazing, and presence or absence of microorganisms. For these data to be scalable in a general model of $C$ fluxes in the rhizosphere, we need to understand the quantitative formulation between a controlling factor of either biological or environmental nature and the relative change in the quantity of a $\mathrm{C}$ flux in response to the change of the ecological factor. A so-called "shared-control" hypothesis has been proposed to be generally applicable to the case of $C$ fluxes in the rhizosphere by Farrar et al. (2003). This hypothesis stipulates that every step in the flow of $C$ from photosynthesis to the final utilization in the rhizosphere contributes to the control of the overall flux. Based on results, primarily from liquid culture experiments, they suggested that photosynthesis exerts the bulk of the control on the size of $\mathrm{C}$ flux into the rhizosphere, and that active or passive exudation controls the $\mathrm{C}$ outflow more than microbial utilization. However, quantitative models describing such shared controls of $\mathrm{C}$ fluxes in the rhizosphere are still lacking because of the complexity involved in such multistep modeling exercises (Toal et al. 2000). Likewise, more complex studies involving experimental setups that closely mimic in situ conditions may further assist in developing a more sophisticated understanding of the controls exerted on the flux of $\mathrm{C}$ by the rhizosphere.

\section{Chemical Composition Of Rhizodeposits In Solls}

As we mentioned earlier, our understanding of the chemical composition of rhizodeposits is still entirely based on data from liquid culture experiments. We know very little about the chemical composition of rhizodeposits in soils 
before transformations by rhizosphere microorganisms, given that the understanding of the chemical nature of rhizodeposits is a prerequisite for a better handle on the ecological functions of rhizodeposits. Hopefully, the dual use of isotope tracers with reporter genes may offer new opportunities in this area of research (Killham and Yeomans 2001).

\section{Carbon Fluxes And The Coevolution Between Plants And SOIL BIOTA}

If higher plants invest a significant amount of fixed carbon into the rhizosphere to support a portion of the soil biota, the coevolution between plants and rhizosphere biota must shape the quantity and the quality of rhizosphere $C$ fluxes through selection and adaptation. Given the known wide range of association types between roots and rhizosphere biota from highly mutualistic (e.g., rhizobium-legume) to totally opportunistic (e.g., free-living bacteria), we know little about how these different types of associations operate in determining the amount and the types of rhizosphere $C$ flows, not to mention the potential role of the complex interactions in the rhizosphere through evolutionary time. This complexity and the associated opportunities for future research are well illustrated in the case of "the free rider" problem in the recent paper by Denison et al. (2003). The "free rider" problem arises when considering microbial intra-species competition in the context of plant-microbe cooperation and mutualisms. Because the benefits (e.g., carbon substrates) gained from an individual plant via microbial cooperation are often used by many individual microbes, those microbial individuals that do not provide the cost of the cooperation (e.g., $\mathrm{N}_{2}$-fixation) yet may equally gain the benefits (often in the form of mutants), or the "free-riders", should have the tendency to replace those microbial individuals that do bear the cost of such cooperation. Yet, this reasoning directly contradicts the fact that plant-microbe cooperation and mutualisms have persisted, presumably, for millions of years. Using this apparent paradox as a thread, Denison et al. (2003) discussed potential mechanisms of plant-microbe cooperation and mutualisms and touched on many intricate connections in the rhizosphere.

\section{ACKNOWLEDGEMENTS}

We thank the help from an anonymous reviewer on an earlier draft. The work of this chapter was supported by National Research Initiative Competitive Grant no. 2003-35107-13716 from the USDA Cooperative State Research, Education, and Extension Service, and a grant from the Kearney Foundation of Soil Science. 


\section{REFERENCES}

Abbadie, L., A. Mariotti, and J. Menaut. 1992. Independence of savanna grass from soil organic matter for their nitrogen supply. Ecology 73:608-613.

Anderson, J.P.E., and K.H. Domsch. 1978. A physiological method for the quantitative measurement of microbial biomass in soils. Soil Biology and Biochemistry 10:215-221.

Arnone, J.A., and J.C. Gordon.1990. Effect of nodulation, nitrogen fixation and $\mathrm{CO}_{2}$ enrichment on the physiology, growth and dry mass allocation of seedlings of Alnus rubra Bong. New Phytologist 116:55-66.

Barber, D.A., and K.B. Gunn. 1974. The effect of mechanical forces on the exudation of organic substances by the roots of cereal plants grown under sterile conditions. New Phytologist 73:69-80.

Bertin, C., X. Yang, and L. Weston. 2003. The role of root exudates and allelochemicals in the rhizosphere. Plant and Soil 256(1):67-83.

Billes, G., H. Rouhier, and P. Bottner. 1993. Modifications of the carbon and nitrogen allocations in the plant (Triticum aestivum L.) soil system in response to increased atmospheric $\mathrm{CO}_{2}$ concentration. Plant and Soil 157:215-225.

Bowden, R.D., K.J. Nadelhoffer, R.D. Boone, J.M. Melillo, and J.B. Garris. 1993. Contributions of aboveground litter, belowground litter, and root respiration to total soil respiration in a temperature mixed hardwood forest. Canadian Journal of Forest Research 23:1402-1407.

Cardon, Z.G., A.D. Czaja, J.L. Funk, and P.L. Vitt. 2002. Periodic carbon flushing to roots of Quercus rubra saplings affects soil respiration and rhizosphere microbial biomass. Oecologia 133:215-223.

Cheng, W. 1996. Measurement of rhizosphere respiration and organic matter decomposition using natural ${ }^{13} \mathrm{C}$. Plant and Soil 183:263-268.

Cheng, W. 1999. Rhizosphere feedbacks in elevated $\mathrm{CO}_{2}$. Tree Physiology 19:313-320.

Cheng, W., and D.C. Coleman. 1990. Effect of living roots on soil organic matter decomposition. Soil Biology and Biochemistry 22:781-787.

Cheng, W., and D.W. Johnson. 1998. Effect of elevated $\mathrm{CO}_{2}$ on rhizosphere processes and soil organic matter decomposition. Plant and Soil 202:167-174.

Cheng W, Kuzyakov Y (2005) Root effects on soil organic matter decomposition. In Zobel RW, Wright SF (eds) Roots and Soil Management: Interactions Between Roots and the Soil, Agronomy Monograph no. 48, ASA-CSSA-SSSA, Madison, Wisconsin, USA.

Cheng, W., D.C. Coleman, C.R. Carroll, and C.A. Hoffman. 1993. In situ measurement of root respiration and soluble carbon concentrations in the rhizosphere. Soil Biology and Biochemistry 25:1189-1196.

Cheng, W., D.C. Coleman, C.R. Carroll, and C.A. Hoffman. 1994. Investigating short-term carbon flows in the rhizospheres of different plant species using isotopic trapping. Agronomy Journal 86:782-791.

Cheng, W., D.A. Sims, Y. Luo, D.W. Johnson, J.T. Ball, and J.S. Coleman. 2000. Carbon budgeting in plant-soil mesocosms under elevated $\mathrm{CO}_{2}$ : locally missing carbon? Global Change Biology 6:99-110.

Cheng, W., D.W. Johnson, and S. Fu. 2003. Rhizosphere effects on decomposition: controls of plant species, phenology, and fertilization. Soil Science Society of America Journal 67:1418-1427.

Craine, J.M., D.A. Wedin, and F.S. Chapin. 1999. Predominance of ecophysiological controls on soil $\mathrm{CO}_{2}$ flux in a Minnesota grassland. Plant and Soil 207:77-86.

Denison, R.F., C. Bledsoe, M. Kahn, F.O. Gaa, E.L. Simms, and L.S. Thomashow. 2003. Cooperation in the rhizosphere and the "free rider" problem. Ecology 84:838-845. 
Dyer, M.I., M.A. Acra, G.M. Wang, D.C. Coleman, D.W. Freckman, S.J. McNaughton, and B.R. Strain. 1991. Source-sink carbon relations in two Panicum coloratum ecotypes in response to herbivory. Ecology 72:1472-1483.

Eissenstat, D.M., and R.D. Yanai. 1997. The ecology of root lifespan. Advances in Ecological Research 27:1-60.

Elliott, E.T., C.V. Cole, B.C. Fairbanks, L.E. Woods, R.J. Bryant, and D.C. Coleman. 1983. Short-term bacterial growth, nutrient uptake, and ATP turnover in sterilized, inoculated and C-amended soil: the influence of $\mathrm{N}$ availability. Soil Biology and Biochemistry 15:85-91.

Farrar, J.F., and D.L. Jones. 2000. The control of carbon acquisition by roots. New Phytologist 147:43-53.

Farrar, J.F., M. Hawes, D. Jones, and S. Lindow. 2003. How roots control the flux of carbon to the rhizosphere. Ecology 84:827-837.

Foster, R.C. 1988. Microenvironments of soil microorganisms. Biology and Fertility of Soils 6:189-203.

$\mathrm{Fu}, \mathrm{S}$., W. Cheng. 2002. Rhizosphere priming effects on the decomposition of soil organic matter in $\mathrm{C}_{4}$ and $\mathrm{C}_{3}$ grassland soils. Plant and Soil 238:289-294.

Garrett, C.J., D.A. Crossley, D.C. Coleman, P.F. Hendrix, K.W. Kisselle, and R.L. Porter. 2001. Impact of the rhizosphere on soil microarthropods in agroecosystems on the Georgia piedmont. Applied Soil Ecology 16:141-148.

Hamilton, E.W., D.A. Frank. 2001. Can plant stimulate soil microbes and their own nutrient supply? Evidence from a grazing tolerant grass. Ecology 82:2397-2402.

Hanson, P.J., N.T. Edwards, C.T. Garten, and J.A. Andrews. 2000. Separating root and soil microbial contributions to soil respiration: A review of methods and observations. Biogeochemistry 48:115-146.

Harris, D., and E.A. Paul. 1991. Techniques for examining the carbon relationships of plantmicrobial symbioses. In: Coleman DC, Fry B (eds) Carbon Isotope Techniques. Academic Press, San Diego, CA, pp. 39-52.

Helal, H.M., and D. Sauerbeck. 1989. Carbon turnover in the rhizosphere. Zeitschrift fur Pflanzenernahrung und Bodenkunde 152:211-216.

Herald, A. 1980. Regulation of photosynthesis by sink activity-the missing link. New Phytologist 86:131-144.

Hirsch, A.M., W.D. Bauer, D.M. Bird, J. Cullimore, B. Tyler, and J. Yoder. 2003. Molecular signals and receptors: Controlling rhizosphere interactions between plants and other organisms. Ecology 84:858-868

Högberg, P., A. Nordgren, N. Buchmann, A.F.S. Taylor, A. Ekblad, M.N. Hogberg, G. Nyberg, M. Ottosson-Lofvenius, and D.J. Read. 2001. Large-scale forest girdling shows that current photosynthesis drives soil respiration. Nature 411:789-792.

Horwath, W.R., K.S. Pregitzer, and E.A. Paul. 1994. C-14 allocation in tree soil systems. Tree Physiology 14:1163-1176.

Houghton, R.A. 1993. Is carbon accumulating in the northern temperate zone? Global Biogeochemical Cycles 7:611-617.

Hungate, B.A., E.A. Holland, R.B. Jackson, F.S. Chapin, H.A. Mooney, and C.B. Field. 1997. The fate of carbon in grasslands under carbon dioxide enrichment. Nature 388:576-579.

Ingham, R.E., J.A. Trofymow, E.R. Ingham, and D.C. Coleman. 1985. Interactions of bacteria, fungi, and their nematode grazers: Effects of nutrient cycling and plant growth. Ecological Monographs 55:119-140.

Jaeger, C.H. III, S.E. Lindow, W. Miller, E. Clark, and M.K. Firestone. 1999. Mapping of sugar and amino acid availability in soil around roots with bacterial sensors of sucrose and tryptophan. Applied and Environmental Microbiology 65:2685-2690.

Johansson, G. 1992. Release of organic C from growing roots of meadow fescue (Festuca pratensis L.). Soil Biology and Biochemistry 24:427-433. 
Jones, D.L., and P.R. Darrah. 1995. Influx and efflux of organic acids across the soil-root interface of Zea mays L. and its implications in rhizosphere C flow. Plant and Soil 173:103-109.

Jones, D.L., J. Farrar, and K.E. Giller. 2003. Associative nitrogen fixation and root exudationWhat is theoretically possible in the rhizosphere? Symbiosis 35:19-28.

Kapulnik, Y. 1991. Nonsymbiotic nitrogen-fixing microorganisms. In: Waisel Y, Eshel A, Kafkafi U (eds) Plant Roots: The Hidden Half. Marcel Dekker, Inc., New York, pp. 703-716.

Killham, K., and C. Yeomans. 2001. Rhizosphere carbon flow measurement and implications: from isotopes to reporter genes. Plant and Soil 232:91-96.

Kuikman, P.J., L.J.A. Lekkerkerk, and J.A. van Veen. 1991. Carbon dynamics of a soil planted with wheat under elevated $\mathrm{CO}_{2}$ concentration. In: Wilson W.S. (ed.) Advances in Soil Organic Matter Research: The Impact on Agriculture and the Environment, vol Special Publication 90. The Royal Society of Chemistry, Cambridge, UK, pp. 267-274.

Kuzyakov, Y., and W. Cheng. 2001. Photosynthesis controls of rhizosphere respiration and organic matter decomposition. Soil Biology and Biochemistry 33:1915-1925.

Kuzyakov, Y., and G. Domanski. 2000. Carbon inputs by plants into the soil. Review. Journal of Plant Nutrition and Soil Science 163:421-431.

Kuzyakov, Y., and G. Domanski. 2002 Model for rhizodeposition and $\mathrm{CO}_{2}$ efflux from planted soil and its validation by C-14 pulse labeling of ryegrass. Plant and Soil 239:87-102.

Kuzyakov, Y., and S.V. Siniakina. 2001. A novel method for separating root-derived organic compounds from root respiration in non-sterile soils. Journal of Plant Nutrition and Soil Science 164:511-517.

Kuzyakov, Y., A. Kretzschmar, and K. Stahr. 1999. Contribution of Lolium perenne rhizodeposition to carbon turnover of pasture soil. Plant and Soil 213:127-136.

Kuzyakov, Y., H. Ehrensberger, and K. Stahr. 2001. Carbon partitioning and below-ground translocation by Lolium perenne. Soil Biology and Biochemistry 33:61-74.

Lambers, H. 1987. Growth, respiration, exudation and symbiotic associations: the fate of carbon translocated to the roots. In: Gregory P.J., and Lake J.V. (eds) Root Development and Function. Cambridge University Press, London, pp. 125-145.

Lekkerkerk, L.J.A., S.C. van De Geijn, and J.A. van Veen. 1990. Effects of elevated atmospheric $\mathrm{CO}_{2}$-levels on the carbon economy of a soil planted with wheat. In: Bouwman, A.F. (ed.) Soils and the Greenhouse Effect. John Wiley \& Sons, pp. 423-429.

Liljeroth, E., J.A. Van Veen, and H.J. Miller. 1990. Assimilate translocation to the rhizosphere of two wheat lines and subsequent utilization by rhizosphere microorganisms at two nitrogen concentrations. Soil Biology and Biochemistry 22:1015-1021.

Luo, Y.Q., L.H. Wu, J.A. Andrew, L. White, R. Matamala, K.W.R. Schafer, and W.H. Schlesinger. 2001. Elevated $\mathrm{CO}_{2}$ differentiates ecosystem carbon processes: Deconvolution analysis of Duke FACE data. Ecological Monographs 71:357-376.

Marschner, H. 1995. Mineral Nutrition of Higher Plants. Academic Press, San Diego.

Marschner, P. 2003. BIOLOG and Molecular Methods to Assess Root-Microbe Interactions in the Rhizosphere. Third International Symposium on Dynamics of Physiological Processes in Woody Roots. School of Plant Biology, University of Western Australia, Perth, Australia, p. 41.

Martin, J.K., and R. Merckx. 1992. The partitioning of photosynthetically fixed carbon within the rhizosphere of mature wheat. Soil Biology and Biochemistry 24:1147-1156.

Matamala, R., and W.H. Schlesinger. 2000. Effects of elevated atmospheric $\mathrm{CO}_{2}$ on fine root production and activity in an intact temperate forest ecosystem. Global Change Biology 6:967-979.

Nguyen, C. 2003. Rhizodeposition of Organic C by plants: mechanisms and controls. Agronomie 23:375-396.

Nguyen, C., C. Todorovic, C. Robin, A. Christophe, and A. Guckert. 1999. Continuous monitoring of rhizosphere respiration after labeling of plant shoots with ${ }^{14} \mathrm{CO}_{2}$. Plant and Soil 212:191-201. 
Norby, R.J., E.G. O'Neill, and R.J. Luxmoore. 1986. Effects of $\mathrm{CO}_{2}$ enrichment on the growth and mineral nutrition of Quercus alba seedlings in nutrient-poor soil. Plant Physiology 82:83-89.

Norby, R.J., P.J. Hanson, E.G. O'Neill, T.J. Tschaplinski, J.F. Weltzin, R.A. Hansen, W.X. Cheng, S.D. Wullschleger, C.A. Gunderson, N.T. Edwards, and D.W. Johnson. 2002. Net primary productivity of a $\mathrm{CO}_{2}$-enriched deciduous forest and the implications for carbon storage. Ecological Applications 12:1261-1266.

Norton, J.M., J.L. Smith, and M.K. Firestone. 1990. Carbon flow in the rhizosphere of ponderosa pine seedlings. Soil Biology and Biochemistry 22:449-455.

Paterson, E., E.A.S. Rattray, and K. Killham. 1996. Effects of elevated $\mathrm{CO}_{2}$ concentration on C-partitioning and rhizosphere C-flow for three plant species. Soil Biology and Biochemistry 28:195-201.

Paterson, E., A. Hodge, B. Thornton, P. Millard, and K. Killham. 1999. Carbon partitioning and rhizosphere $\mathrm{C}$-flow in Lolium perenne as affected by $\mathrm{CO}_{2}$ concentration, irridiance and belowground conditions. Global Change Biology 5:669-678.

Payne, W.J. 1970. Energy yields and growth of heterotrophs. Annual Review of Microbiology 24:17-52.

Phillips, D.A., H. Ferris, D.R. Cook, and D.R. Strong. 2003. Molecular control points in rhizosphere food webs. Ecology 84:816-826.

Post, W.M.,T.H. Peng, W.R. Emmanuel, A.W. King, V.H. Dale, and D.L. DeAngelis. 1990. The global carbon cycle. American Scientist 78:310-326.

Rouhier, H., G. Billes, L. Billes, and P. Bottner. 1996. Carbon fluxes in the rhizosphere of sweet chestnut seedlings (Castanea sativa) grown under two atmospheric $\mathrm{CO}_{2}$ concentrations: ${ }^{14} \mathrm{C}$ partitioning after pulse labelling.Plant and Soil 180:101-111.

Ryan, M.G., R.M. Hubbard, S. Pongracic, R.J. Raison, and R.E. McMuurtrie. 1996. Foliage, fineroot, woody tissue and stand respiration in Pinus radiata in relation to nitrogen status. Tree Physiology 16:333-343.

Schimel, D.S. 1995. Terrestrial ecosystems and the carbon cycle. Global Change Biology 1:77-91.

Thomas, R.B., D.D. Richter, H. Ye, P.R. Heine, and B.R. Strain. 1991. Nitrogen dynamics and growth of seedlings of an $\mathrm{N}$-fixing tree (Gliricidia sepium) exposed to elevated atmospheric carbon dioxide. Oecologia 8:415-421.

Tissue, D.T., J.P. Megonigal, and R.B. Thomas. 1997. Nitrogenase activity and $\mathrm{N}_{2}$ fixation are stimulated by elevated $\mathrm{CO}_{2}$ in a tropical $\mathrm{N}_{2}$-fixing tree. Oecologia 109: 28-33.

Toal, M.E., C. Yeomans, K. Killham, and A.A. Meharg. 2000. A review of rhizosphere carbon flow modeling. Plant and Soil 222:263-281.

Todorovic, C., C. Nguyen, C. Robin, and A. Guckert. 2001. Root and microbial involvement in the kinetics of C-14-partitioning to rhizosphere respiration after a pulse labeling of maize assimilates. Plant and Soil 228:179-189.

Van Veen, J.A., E. Liljeroth, L.J.A. Lekkerkerk, and S.C. Van de Geijn. 1991. Carbon fluxes in plant-soil systems at elevated atmospheric $\mathrm{CO}_{2}$ levels. Ecological Applications 1:175-181.

Warembourg, F.R., and G. Billes. 1979. Estimating carbon transfers in the plant rhizosphere. In: Harley, J.L., and Russell, R.S. (eds) The soil root interface. Academic Press, London, UK, pp. 182-196.

Warembourg, F.R., and H.D. Estelrich. 2000. Towards a better understanding of carbon flow in the rhizosphere: a time-dependent approach using carbon-14. Biology and Fertility of Soils 30:528-534.

Warembourg, F.R., C. Roumet, and F. Lafont. 2003. Differences in rhizosphere carbonpartitioning among plant species of different families. Plant and Soil 256:347-357.

Whipps, J.M. 1990. Carbon Economy. In: Lynch, J.M. (ed.) The Rhizosphere. John Wiley \& Sons, New York. 
Whipps, J.M. 2001. Microbial interactions and biocontrol in the rhizosphere. Journal of Experimental Botany 52:487-511.

Whipps, J.M., and J.M. Lynch. 1985. Energy losses by the plant in rhizodeposition. Annual Proceedings of the Phytochemical Society of Europe 26:59-71.

Zak, D.R., and K.S. Pregitzer. 1998. Integration of ecophysiological and biogeochemical approaches to ecosystem dynamics. In: Groffman, P.M. (ed.) Successes, Limitations, and Frontiers in Ecosystem Science, pp. 372-403. 


\section{Chapter No: 02}

Query No

AUl:

AU2:

AU3:

AU4:

AU5:

AU6:

\section{Query}

Kuzyakov 2002 is not listed in the References. Please provide.

Shall we change "Nutrient... as low weight molecular compounds... hairs" to "Nutrient... as low molecular weight compounds... hairs"? Please advise.

Shall we change "Recent advances... low-weight molecular compounds... providing both spatial... sites, as well as offering... roots" to "Recent advances... low molecular weight compounds... both providing spatial... sites and offering... roots"? Please advise.

Paterson et al. 1996 and 1999 are not cited in the text. Please provide.

Rouhier et al. 1996 is not cited in the text. Please provide.

Please provide publisher details. 